Brazilian Journal

of Chemical

\title{
STUDY OF THE EFFECT OF FUNCTIONALIZATION OF CARBON NANOTUBES ON GAS SEPARATION
}

\author{
M. Babaei ${ }^{1}$, M. Anbia ${ }^{2 *}$ and M. Kazemipour ${ }^{1}$ \\ ${ }^{1}$ Islamic Azad University, Department of Chemistry, Kerman, Iran. ORCID: 0000-0002-0615-118X; ORCID: 0000-0002-8485-3291 \\ ${ }^{2}$ Iran University of Science and Technology, Faculty of Chemistry, Research Laboratory of Nanoporous Materials, Tehran, Iran. \\ E-mail: anbia@iust.ac.ir - ORCID: 0000-0002-2142-3219
}

(Submitted: June 22, 2018 ; Revised: January 3, 2019 ; Accepted: February 2, 2019)

\begin{abstract}
In order to improve the adsorption capacity and selectivity of $\mathrm{CO}_{2} / \mathrm{CH}_{4}$ and $\mathrm{CO}_{2} / \mathrm{N}_{2}$, we have functionalized multi-walled carbon nanotubes (MWCNT) with 3-aminopropyltriethoxysilane (APTES). The functionalized MWCNT was characterized by Fourier transform infrared (FT-IR), energy dispersive X-ray spectroscopy (EDX) and BET analysis. $\mathrm{CO}_{2}, \mathrm{CH}_{4}$ and $\mathrm{N}_{2}$ adsorption at two different temperatures and $\mathrm{P}<5$ bar on the functionalized MWCNTs was investigated by the volumetric method. The selectivity of the functionalized MWCNTs for $\mathrm{CO}_{2} / \mathrm{CH}_{4}$ and $\mathrm{CO}_{2} / \mathrm{N}_{2}$ was studied and compared with MWCNTs. The functionalized MWCNTs show higher adsorption capacity of $\mathrm{CO}_{2}$ and selectivity of $\mathrm{CO}_{2} / \mathrm{CH}_{4}$ and $\mathrm{CO}_{2} / \mathrm{N}_{2}$ in comparison with the MWCNTs at different pressures. The highest $\mathrm{CO}_{2} / \mathrm{CH}_{4}$ and $\mathrm{CO}_{2} / \mathrm{N}_{2}$ selectivities for the functionalized MWCNTs were 6.78 and 26.14, respectively, at a pressure of 0.2 bar and at $298 \mathrm{~K}$. Two of the most common adsorption models, the Langmuir and Sips isotherms, were used to correlate the experimental data of $\mathrm{CO}_{2}$ and $\mathrm{CH}_{4}$ adsorption on the adsorbents. The results confirm that the functionalized MWCNTs are promising materials for the separation and purification of gases.

Keywords: Carbon nanotubes; Functionalization; Adsorption isotherm; Gas separation.
\end{abstract}

\section{INTRODUCTION}

The continuous use of fossil fuels has led to emission of greenhouse gases and global warming, which is one of the most important environmental issues facing human beings. Two ways can decrease the emission of $\mathrm{CO}_{2}$ : (1) carbon capture and storage (CCS) and (2) use of clean and renewable energy sources. An ideal replacement for fossil fuels is natural gas because it releases less greenhouse gases (Chong et al., 2016; Lajunen et al., 2016). Natural gas is mainly composed of methane, but contains impurities such as $\mathrm{CO}_{2}, \mathrm{H}_{2} \mathrm{~S}$ and $\mathrm{H}_{2} \mathrm{O}$, which decrease the energy content and corrode pipelines (Campo et al., 2016; Faramawy et al., 2018; Kajama et al., 2018). Therefore, removing these components from natural gas is important in its industrial application. In order to separate the gas mixtures into their component parts, a variety of methods have been proposed such as solvent absorption, membrane separation, adsorptive separation, and chemical conversion. Among the gas separation methods, adsorptive separation appears to be important for gas separation/purification and storage technology owing to its simplicity, low cost, ease of control, and high energy performance (Peng et al., 2006; Babarao et al., 2009; Li et al., 2009).

A lot of porous materials, such as zeolites (Cavenati et al., 2004; Su et al., 2010), activated alumina (Luebke et al., 2006; Carreon et al., 2008), metal organic frameworks (MOFs) (Belmabkhout et al., 2009; Xiang et al., 2010) and carbonaceous materials (Przepiórski et al., 2004; Lu et al., 2008; Budaeva et al., 2010; Palmer et al., 2011; Lei et al., 2014) have been utilized in gas adsorption/separation processes. Recently, there is a lot of interest in utilizing CNTs for $\mathrm{CO}_{2}$ adsorption due to their distinctive chemical and physical properties, high thermal and chemical stability and also the reversible nature of the $\mathrm{CO}_{2}$ adsorption process upon increasing

\footnotetext{
* Corresponding author: M. Anbia - E-mail: anbia@iust.ac.ir
} 
the temperature ( $\mathrm{Su}$ et al., 2009; Shen et al., 2010; Khoerunnisa et al., 2014; Wang et al., 2016).

Investigation of the effect of surface functional groups on the textural properties of carbonaceous materials such as surface area and pore size distribution and also on the adsorption/separation of gases has shown that modification of the surface of carbonaceous materials could cause selective adsorption of one molecule over another (Bezerra et al., 2011; Su et al., 2011; Hu et al., 2017; Keller et al., 2018). The functionalization of CNTs can be performed with a wide range of functional groups including oxygen- and nitrogen-containing groups. Incorporation of nitrogen-containing groups enhances the basicity of CNTs and thus can improve capacity and selectivity of carbonaceous materials in adsorption of acidic gases such as $\mathrm{CO}_{2}$ and $\mathrm{SO}_{2}$ (Fatemi et al., 2011; Gui et al., 2013; Khalili et al., 2013; Irani et al., 2017; Zhou et al., 2017).

A large number of experimental studies on single gas adsorption in carbon nanotubes have been reported in literature, but experimental studies on the gas compounds and separation of their mixtures, especially on CNTs, are seldom found. Therefore, further studies are needed to improve the performance of CNTs for gas separation. In this work, a kind of multiwall carbon nanotubes (MWCNT) is functionalized by 3-aminopropyltriethoxysilane (APTES) and its application for $\mathrm{CO}_{2}$ separation studied. The adsorption isotherms for pure components are obtained at two temperatures. The adsorption capacity and selectivity of the MWCNTs are investigated at $298 \mathrm{~K}$ and $348 \mathrm{~K}$.

\section{EXPERIMENTAL SECTION}

\section{Materials}

Commercial MWCNTs (Neutrino Corporation) with inner diameter 5-10 $\mathrm{nm}$ and $95 \%$ purity were used in this study. Nitric acid 65\% $\left(\mathrm{HNO}_{3}\right)$, sulfuric acid 95-97\% $\left(\mathrm{H}_{2} \mathrm{SO}_{4}\right)$ and APTES were obtained from E. Merck (Germany). The solvent used in this work was ethanol obtained from Merck. The $\mathrm{CO}_{2}, \mathrm{CH}_{4}$ and $\mathrm{N}_{2}$ gas cylinders with purity $>99.999$ used in adsorption experiments, were supplied by Sepehr Gas Kavian Co.

\section{Preparation of adsorbent}

Acid pre-treatment of MWCNTs was performed to achieve two aims: (1) removal of metal catalyst particles from the pristine MWCNTs and (2) carboxylation of the MWCNTs to introduce carboxyl groups on the MWCNT surface prior to amine functionalization. The oxidized MWCNT (MWCNT-COOH) was prepared by adding $500 \mathrm{mg}$ of the calcined MWCNTs to $80 \mathrm{~mL}$ of a mixture of $\mathrm{H}_{2} \mathrm{SO}_{4} / \mathrm{HNO}_{3}(3: 1 \mathrm{v} / \mathrm{v})$ via sonication for $1 \mathrm{~h}$. Then the solution was stirred with a magnetic stirrer, at room temperature for $24 \mathrm{~h}$. The mixture was diluted with distilled water and filtered through a 0.2 $\mu \mathrm{m}$ fiber filter and washed with distilled water several times until the $\mathrm{pH}$ increased to neutral $(\mathrm{pH} 7)$. The carboxylated MWCNT were then dried in a vacuum drying oven at $100^{\circ} \mathrm{C}$ for $4 \mathrm{~h}$ (Anbia et al., 2012).

The amine functionalization was then carried out on the pretreated MWCNTs using APTES. The pre-treated MWCNTs were dispersed into bottles containing APTES solution $(10 \mathrm{~mL}$ of $97 \%$ APTS $+90 \mathrm{~mL}$ of ethanol) and continuously stirred with a magnetic stirrer at room temperature for $72 \mathrm{~h}$. The mixture was filtered through a $0.2 \mu \mathrm{m}$ fiber filter and washed repeatedly with ethanol and deionized water to remove excess APTES. Finally the filtered solid was dried in an oven at $100{ }^{\circ} \mathrm{C}$ for $6 \mathrm{~h}$ and denoted as N-MWCNT.

\section{Characterization}

The surface functional groups of the modified sorbents were evaluated by FTIR spectra obtained with a FT-IR DIGILAB FTS 7000 spectrometer. The chemical composition of N-MWCNT was studied by energy dispersive X-ray spectroscopy (EDX). The specific surface area and the pore diameter of the adsorbents were obtained by $\mathrm{N}_{2}$ adsorption-desorption isotherms at $77 \mathrm{~K}$ with a volumetric sorption analyzer.

\section{Gas adsorption measurement}

To evaluate the $\mathrm{CO}_{2}, \mathrm{CH}_{4}$ and $\mathrm{N}_{2}$ adsorption capacity of adsorbents at two different temperatures, a laboratory setup based on the volumetric method was used, which is schematically shown in Fig. 1. At first, 0.5 $\mathrm{g}$ of adsorbent was poured into the adsorption reactor and then attached to the system. To ensure that there is no leak in the connections, the system was checked with the inert Helium gas flow. In order to degas the system, the valves $6,7,8,9$ were opened and other valves closed; then, the system was evacuated with the vacuum pump for $1.5 \mathrm{~h}$ at $120^{\circ} \mathrm{C}$. After degassing the adsorption system, temperature was decreased to ambient temperature. To perform the adsorption test, we opened the valves $1,3,5,6,7$ and 8 while other valves were closed. The pressure drop observed during the process was the result of gas adsorption and some dead volumes in the reactor. We could exactly measure

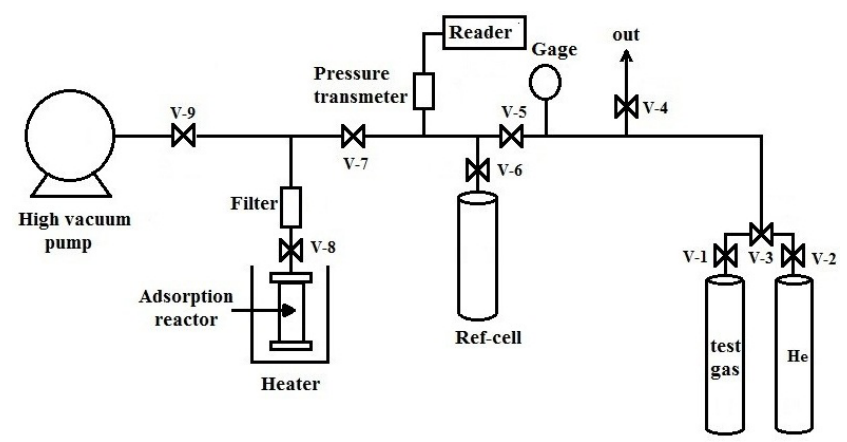

Figure 1. Schematic of volumetric system for adsorption test. 
pressure reduction relevant to the gas adsorption by measuring the dead volumes via helium test. The $\mathrm{CO}_{2}$, $\mathrm{CH}_{4}$ and $\mathrm{N}_{2}$ used for the experiment were of $99.99 \%$ purity (Jin et al., 2015; Li et al., 2016; Jin et al. 2018).

\section{RESULT AND DISCUSSION}

\section{Adsorbents characterization}

Fig. 2 shows the FTIR spectra of calcined and amine modified MWCNTs. In the calcined MWCNT spectrum, the peak at $1630 \mathrm{~cm}^{-1}$ is attributed to $\mathrm{C}=\mathrm{C}$ bonds of nanotubes. The peak at $3432 \mathrm{~cm}^{-1}$ is associated with hydroxyl groups $(-\mathrm{OH})$ on the surface of the adsorbents. The IR spectrum of N-MWCNT shows significant bands at 3439, 2850-2960, 1743, 1355$1488,1030-1100$ and $803 \mathrm{~cm}^{-1}$ which are associated with $\mathrm{CH}$ stretching from $\mathrm{CH}_{2} \mathrm{CH}_{2} \mathrm{CH}_{2}-\mathrm{NH}_{2}$ groups, $\mathrm{N}-\mathrm{H}$ stretch, $\mathrm{N}-\mathrm{H}_{2}$ deformation of hydrogen-bonded amine group (Chang et al., 2003; Huang et al., 2003), $\mathrm{Si}-\mathrm{O}-\mathrm{Si}(\mathrm{C})$ and $\mathrm{O}-\mathrm{Si}-\mathrm{O}$ vibrations (Jing et al., 2002; Zhang et al., 2005), respectively. The presence of these peaks confirms the incorporation of APTES on the surface of MWCNTs.

In order to confirm the incorporation of APTES on the surface of MWCNTs, an EDX experiment was performed with a LN (Liquid Nitrogen) free Energy Dispersive detector (SAMx SDD detector) attached to a SEM (Philips XL-30). The results of EDX elemental microanalysis of the N-MWCNT are listed in Table 1.

Figs. 3 and 4 show the $\mathrm{N}_{2}$ adsorption/desorption isotherms and the $\mathrm{BJH}$ pore size distribution of MWCNT and N-MWCNT. It is seen that the modified MWCNTs have less adsorption capacity of $\mathrm{N}_{2}$, because a smaller amount of porosity is retained after the incorporation of APTES on the modified MWCNT surface. The textural properties of the adsorbents are given in Table 1. It is seen that the surface area has decreased but the average pore diameter has increased. The decrease of the surface area could be explained by the blockage of pore entrances due to the formation of the amine groups on the surface of N-MWCNT and

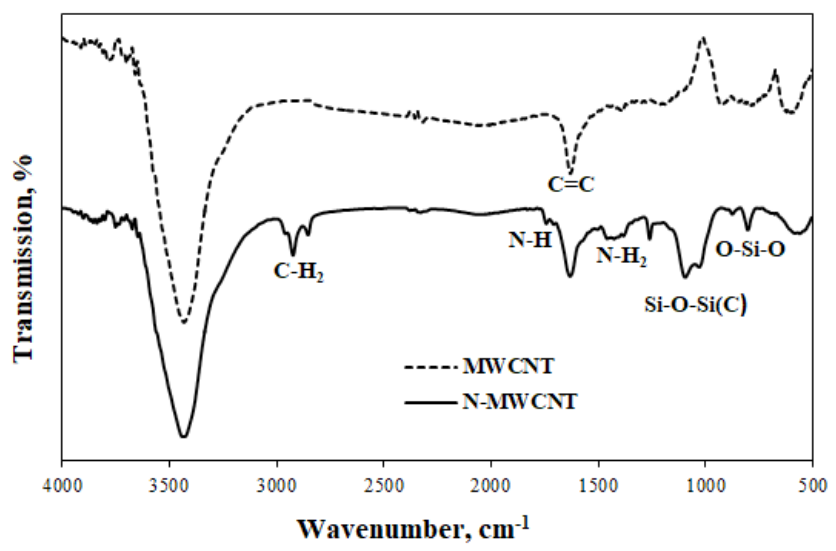

Figure 2. FT-IR spectra of MWCNT and N-MWCNT.

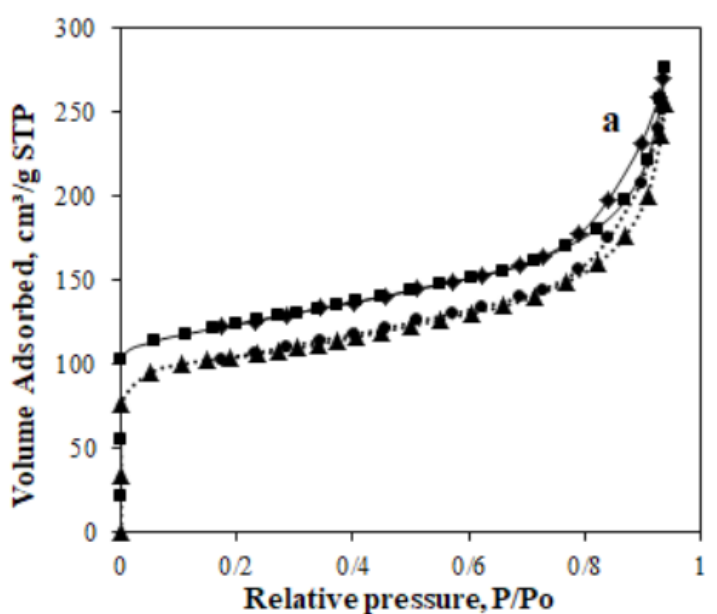

Figure 3. $\mathrm{N}_{2}$ adsorption-desorption isotherms of a) MWCNT and b) N-MWCNT at $77 \mathrm{~K}$.

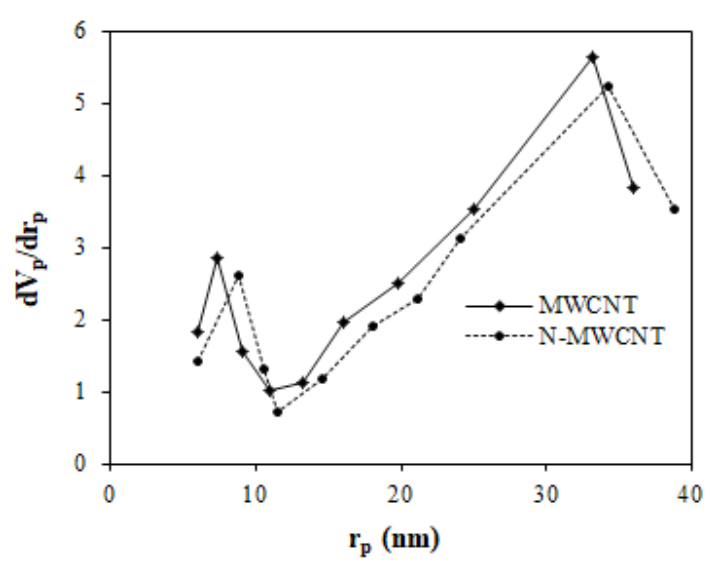

Figure 4. BJH pore size distribution of MWCNT and N-MWCNT.

Table 1. Textural properties and EDX analysis of the MWCNT and N-MWCNT (elemental composition (atomic \%)).

\begin{tabular}{ccc}
\hline Adsorbate & MWCNT & N-MWCNT \\
\hline SBET $\left(\mathrm{m}^{2} \mathrm{~g}^{-1}\right)$ & $>200$ & 137 \\
Mean pore diameter $(\mathrm{nm})$ & 7.4 & 8.6 \\
$\mathrm{C}$ & - & 78.65 \\
$\mathrm{~N}$ & - & 4.24 \\
$\mathrm{O}$ & - & 10.94 \\
$\mathrm{Si}$ & - & 6.16 \\
\hline
\end{tabular}

the increase of the average pore diameter is due to the removal of the amorphous carbon and the catalysts during the purification process by acidic solution (Ioannatos et al., 2010; Su et al., 2009).

\section{Adsorption measurement}

Fig. 5 shows the pure $\mathrm{CO}_{2}, \mathrm{CH}_{4}$ and $\mathrm{N}_{2}$ adsorption isotherms on MWCNT and N-MWCNT at $298 \mathrm{~K}$. The $\mathrm{CO}_{2}, \mathrm{CH}_{4}$ and $\mathrm{N}_{2}$ adsorption capacities of MWCNT and N-MWCNT at $298 \mathrm{~K}$ and $348 \mathrm{~K}$ and $\mathrm{P}=1$ bar are given in Table 2.

As expected, adsorption capacity of the three gases was enhanced after amine modification of MWCNTs. 


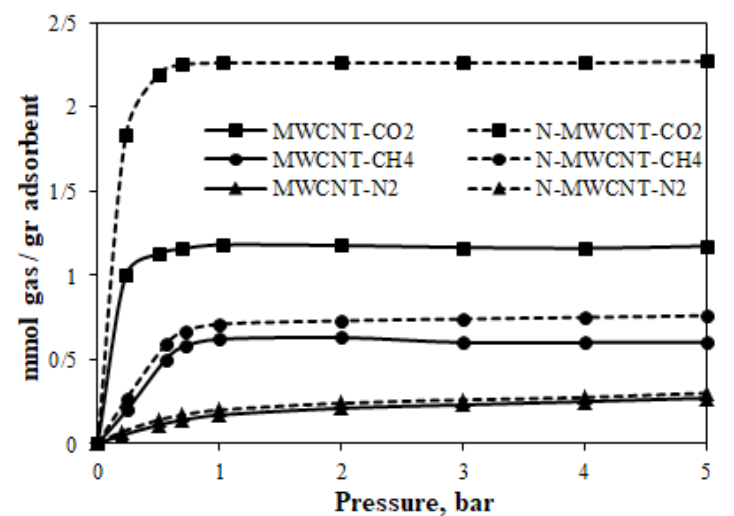

Figure 5. Adsorption isotherms of $\mathrm{CO}_{2}, \mathrm{CH}_{4}$ and $\mathrm{N}_{2}$ on MWCNT and N-MWCNT at $298 \mathrm{~K}$.

Table 2. Gas adsorption capacities of MWCNT and $\mathrm{N}-\mathrm{MWCNT}$ at two temperatures and 1 bar.

\begin{tabular}{ccccccc}
\hline \multirow{3}{*}{ Adsorbent } & \multicolumn{5}{c}{ Gas adsorption capacity (mmol/g) } \\
\cline { 2 - 7 } & \multicolumn{3}{c|}{$\mathbf{2 9 8 ~ K}$} & \multicolumn{4}{c}{$\mathbf{3 4 8 ~ K}$} \\
\cline { 2 - 7 } & $\mathbf{C O}_{\mathbf{2}}$ & $\mathbf{C H}_{\mathbf{4}}$ & $\mathbf{N}_{\mathbf{2}}$ & $\mathbf{C O}_{\mathbf{2}}$ & $\mathbf{C H}_{\mathbf{4}}$ & $\mathbf{N}_{\mathbf{2}}$ \\
\hline MWCNT & 1.19 & 0.63 & 0.17 & 1.02 & - & 0.09 \\
N-MWCNT & 2.26 & 0.71 & 0.2 & 1.99 & - & 0.17 \\
\hline
\end{tabular}

However, as seen in Fig. 5, the N-MWCNT presents a significant increase in the adsorption capacity of $\mathrm{CO}_{2}$ in comparison with $\mathrm{CH}_{4}$ and $\mathrm{N}_{2}$ which may be due to the reaction between the surface amine groups with the $\mathrm{CO}_{2}$ molecules and also because of the high quadrupole moment of $\mathrm{CO}_{2}$ molecules. Chemical reactions between amine groups and $\mathrm{CO}_{2}$ produce the carbamate species according to Eq. (1):

$\mathrm{CO}_{2}+2 \mathrm{RNH}_{2} \leftrightarrow \mathrm{RNH}_{3}^{+}+\mathrm{RNHCOO}^{-}$

$\mathrm{RNHCOO}^{-}+\mathrm{H}_{2} \mathrm{O} \leftrightarrow \mathrm{RNH}_{2}+\mathrm{HCO}_{3}^{-}$

However, as seen in Table 2, the $\mathrm{CO}_{2}$ and $\mathrm{N}_{2}$ adsorption capacity decreases with increasing temperature. The decrease of adsorption capacity with rising temperature implies that the adsorption process is exothermic.

Two of the most common adsorption models, the Langmuir (Garnier et al., 2011) and Sips (Foo et al., 2010) isotherms, were used to correlate the experimental data of $\mathrm{CO}_{2}$ and $\mathrm{CH}_{4}$ adsorption on MWCNT and N-MWCNT at $298 \mathrm{~K}^{4}$. The values of model parameters are given in Table 3. The Langmuir isotherm corresponds to homogeneous adsorbent surfaces (Purna Chandra Rao et al., 2006). The Langmuir isotherm is represented by the following equation:

$q=q_{m} \frac{b P}{(1+b P)}$ where $\mathrm{q}$ is the adsorbed capacity $\left(\mathrm{mmol} \mathrm{g} \mathrm{g}^{-1}\right)$ at equilibrium pressure $\mathrm{P}, \mathrm{q}_{\mathrm{m}}\left(\mathrm{mmol} \mathrm{g}^{-1}\right)$ and $\mathrm{b}\left(\mathrm{KPa}^{-1}\right)$ are the maximum amount of gas adsorbed $\left(\mathrm{mmol} \mathrm{g}^{-1}\right)$ and the Langmuir constant, respectively.

The Sips isotherm is the combined formula of the Langmuir and Freundlich equations, which is given by Eq.(4):

$q=q_{m} \frac{(b P)^{1 / n}}{1+(b P)^{1 / n}}$

where $\mathrm{q}\left(\mathrm{mmol} \mathrm{g}^{-1}\right)$ is the amount of gas adsorbed at equilibrium pressure of $\mathrm{P}(\mathrm{KPa}), \mathrm{q}_{\mathrm{m}}\left(\mathrm{mmol} \mathrm{g}^{-1}\right)$ is the maximum adsorption capacity, $\mathrm{b}\left(\mathrm{KPa}^{-1}\right)$ is the adsorption equilibrium constant which shows the adsorbate affinity for the surface of adsorbent, and $\mathrm{n}$ is the heterogeneity parameter (Do, 1998).

The fitting accuracy of the proposed model for the experimental data was estimated by an error function based on the average percent deviation calculated according to:

$$
\text { ARE } \%=\frac{100}{N} \sum_{i=1}^{N}\left|\frac{q_{i}^{\text {exp }}-q_{i}^{\text {cal }}}{q_{i}^{\text {exp }}}\right|
$$

where ARE (\%) is the average percent deviation, $\mathrm{N}$ is the number of data points available in the adsorption equilibrium isotherms, and $\mathrm{q}^{\mathrm{exp}}$ and $\mathrm{q}^{\text {cal }}$ are the experimental and calculated amounts adsorbed $(\mathrm{mmol} / \mathrm{g})$, respectively.

As shown in Table 3, between the two isotherms mentioned above, the Sips isotherm with high correlation coefficients $\left(\mathrm{R}^{2}>0.99\right)$ and an average percent deviation value of less than $3 \%$ provides the best model for adsorbents, and presents the excellent agreement between the model parameters and the experimental data, which indicates the heterogeneous nature of the adsorbent surface.

Comparisons of the $\mathrm{CO}_{2}$ adsorption capacities of the adsorbents used in this study and other porous materials are given in Table 4.

Table 3. Langmuir and Sips isotherm parameters for the adsorption of gases on adsorbents at $298 \mathrm{~K}$.

\begin{tabular}{lcccc}
\hline \multirow{2}{*}{ Adsorbent } & \multicolumn{2}{c}{$\mathbf{C O}_{\mathbf{2}}$} & \multicolumn{2}{c}{$\mathbf{C H}_{\mathbf{4}}$} \\
\cline { 2 - 5 } Sips & MWCNT N-MWCNT & MWCNT N-MWCNT \\
q $\left(\mathrm{mmol}_{\mathrm{y}} \mathrm{g}\right)$ & 1.195 & 2.30 & 0.614 & 0.731 \\
$\mathrm{~b}\left(\mathrm{KPa}^{-1}\right)$ & 108.2 & 231.9 & 3.22 & 3.239 \\
$\mathrm{n}$ & 3.45 & 4.30 & 0.34 & 0.430 \\
$\mathrm{R}^{2}$ & 0.991 & 0.995 & 0.994 & 0.999 \\
$\mathrm{ARE} \%$ & 0.595 & 1.76 & 2.53 & 2.95 \\
\hline $\mathrm{Langmuir}$ & & & & \\
$\mathrm{q}_{\mathrm{m}}(\mathrm{mmol} / \mathrm{g})$ & 1.36 & 2.33 & 0.671 & 0.779 \\
$\mathrm{~b}\left(\mathrm{KPa}^{-1}\right)$ & 25.68 & 19.63 & 3.56 & 3.87 \\
$\mathrm{R}^{2}$ & 0.997 & 0.986 & 0.914 & 0.957 \\
$\mathrm{ARE} \%$ & 4.71 & 3.09 & 6.5 & 9.71 \\
\hline
\end{tabular}


Table 4. Comparison of the $\mathrm{CO}_{2}$ adsorption capacity of the MWCNT and N-MWCNT with other porous materials.

\begin{tabular}{cccc}
\hline Adsorbent & $\begin{array}{c}\mathbf{C O}_{\mathbf{2}} \text { adsorption } \\
\text { capacity }(\mathbf{m g} / \mathbf{g})\end{array}$ & Conditions & Reference \\
\hline MCM-48-PEHA-DEA & 22.44 & $298 \mathrm{~K}$ & Anbia et al. (2012) \\
Plasma functionalized CNT & 12.6 & $308 \mathrm{~K}$ & Babu et al. (2013) \\
MWCNT-APTES & 25.0 & $298 \mathrm{~K}$ & Lu et al. (2008) \\
MWCNT-APTES & 40.0 & $323 \mathrm{~K}$ & Su et al. (2011) \\
MWCNT-NH2. & 88.0 & $298 \mathrm{~K}$ & Ghaznavi et al. (2012) \\
MWCNT-APTES & 75.4 & $333 \mathrm{~K}$ & Gui et al. (2013) \\
MWCNT & 52.36 & $298 \mathrm{~K}$ & This study \\
N-MWCNT & 99.44 & $298 \mathrm{~K}$ & This study \\
N-MWCNT & 87.56 & $348 \mathrm{~K}$ & This study \\
\hline
\end{tabular}

\section{Adsorption selectivity for gases}

The pure component selectivity for gases was obtained from their adsorption isotherms. By applying Eq. (6) (Pawar et al., 2009), the adsorption selectivity of gas 1 over gas 2 can be calculated, where $\mathrm{V}_{1}$ and $\mathrm{V}_{2}$ are the volumes of gases 1 and 2 adsorbed at a certain temperature and pressure, respectively.

$$
\mathrm{A}_{1 / 2}=\frac{\mathrm{V}_{1}}{\mathrm{~V}_{2 \cdot \mathrm{T}, \mathrm{P}}}
$$

The adsorption selectivities of $\mathrm{CO}_{2} / \mathrm{CH}_{4}$ on MWCNT and N-MWCNT at 1 bar pressure and $298 \mathrm{~K}$ are 1.9 and 3.18, respectively. As is clear, the N-MWCNT has higher selectivity to $\mathrm{CO}_{2}$ than MWCNT. This is due to the increase of the cationic surface of carbon nanotubes which is produced by amine groups and also because of the high quadrupole moment of $\mathrm{CO}_{2}$ molecules.
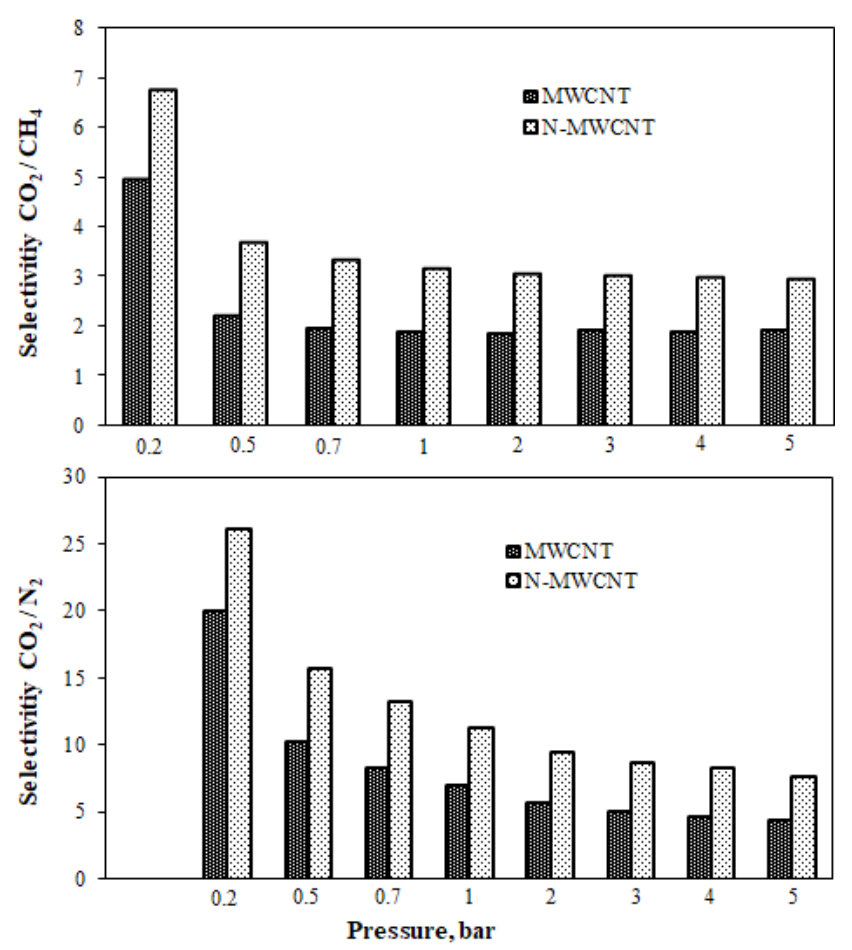

Figure 6. Selectivities of $\mathrm{CO}_{2} / \mathrm{CH}_{4}$ and $\mathrm{CO}_{2} / \mathrm{N}_{2}$ on MWCNT and N-MWCNT at $298 \mathrm{~K}$.
Fig. 6 shows the adsorption selectivities of $\mathrm{CO}_{2} /$ $\mathrm{CH}_{4}$ and $\mathrm{CO}_{2} / \mathrm{N}_{2}$ on MWCNT and N-MWCNT at different pressures and $298 \mathrm{~K}$. The $\mathrm{CO}_{2} / \mathrm{CH}_{4}$ selectivity decreases with increasing pressure. At high pressures, the adsorption of $\mathrm{CH}_{4}$ becomes more significant than that of $\mathrm{CO}_{2}$. The smaller and flat molecules of $\mathrm{CO}_{2}$ can easily diffuse through the pore mouths of nanotubes at lower pressures, whereas large molecules of $\mathrm{CH}_{4}$ require higher pressure to enter the pores (Fatemi et al., 2011).

The selectivity of $\mathrm{CO}_{2} / \mathrm{N}_{2}$ on N-MWCNT is higher than on MWCNT. According to the quadrupole moment of $\mathrm{CO}_{2}$ and $\mathrm{N}_{2}$ molecules as well as the size of the molecules, this is justified. These results suggest that N-MWCNT is a promising candidate for separation and purification of $\mathrm{CO}_{2}$ from various gas mixtures by an adsorptive process.

\section{CONCLUSION}

The gas adsorption capacities on the functionalized MWCNT have been studied. The adsorption capacity of $\mathrm{CO}_{2}, \mathrm{CH}_{4}$ and $\mathrm{N}_{2}$ is enhanced after amine modification of MWCNTs. However, the N-MWCNT presents a significant increase in the adsorption capacity of $\mathrm{CO}_{2}$ in comparison with $\mathrm{CH}_{4}$ and $\mathrm{N}_{2}$. The $\mathrm{CO}_{2} / \mathrm{CH}_{4}$ and $\mathrm{CO}_{2} / \mathrm{N}_{2}$ selectivities were improved for N-MWCNT at $298 \mathrm{~K}$. Selectivity of N-MWCNT for a $\mathrm{CO}_{2} / \mathrm{CH}_{4}$ mixture (6.78) at $298 \mathrm{~K}$ and $\mathrm{p}=0.2$ bar was higher than that of MWCNT (4.99), because $\mathrm{CO}_{2}$ molecules have high quadrupole moment while $\mathrm{CH}_{4}$ molecules do not have a quadrupole moment. Selectivities of N-MWCNT and MWCNT for the $\mathrm{CO}_{2} / \mathrm{N}_{2}$ mixture at $\mathrm{p}=0.2$ bar and $298 \mathrm{~K}$ were 26.14 and 19.96, respectively. It is concluded that $\mathrm{N}-\mathrm{MWCNT}$ is a promising material for $\mathrm{CO}_{2}$ capture from gas mixtures.

\section{ACKNOWLEDGMENTS}

The authors are grateful to the Research Council of Iran University of Science and Technology (Tehran) and Islamic Azad University, Kerman branch for the financial support of this project. 


\section{REFERENCES}

Anbia, M., Hoseini, V. Development of MWCNT@ MIL-101 hybrid composite with enhanced adsorption capacity for carbon dioxide. Chemical Engineering Journal, 191, 326-330 (2012). https:// doi.org/10.1016/j.cej.2012.03.025

Anbia, M., Hoseini, V., Mandegarzad, S. Synthesis and characterization of nanocomposite MCM-48PEHA-DEA and its application as $\mathrm{CO}_{2}$ adsorbent. Korean Journal of Chemical Engineering, 29, 1776-1781 (2012). https://doi.org/10.1007/s11814012-0090-4

Babarao, R., Jiang, J. Unprecedentedly high selective adsorption of gas mixtures in rho zeolite-like metal- organic framework: a molecular simulation study. Journal of the American Chemical Society, 131, 11417-11425 (2009). https://doi.org/10.1021/ ja901061j

Babu, D. J., Lange, M., Cherkashinin, G., Issanin, A., Staudt, R., Schneider, J. J. Gas adsorption studies of $\mathrm{CO}_{2}$ and $\mathrm{N}_{2}$ in spatially aligned double-walled carbon nanotube arrays. Carbon, 61,616-623(2013). https://doi.org/10.1016/j.carbon.2013.05.045

Belmabkhout, Y., Serna-Guerrero, R., Sayari, A. Adsorption of $\mathrm{CO}_{2}$-containing gas mixtures over amine-bearing pore-expanded MCM-41 silica: application for gas purification. Industrial \& Engineering Chemistry Research, 49, 359-365 (2009). https://doi.org/10.1021/ie900837t

Bezerra, D. P., Oliveira, R. S., Vieira, R. S., Cavalcante, C. L., Azevedo, D. C. S. Adsorption of $\mathrm{CO}_{2}$ on nitrogen-enriched activated carbon and zeolite 13X. Adsorption, 17, 235-246 (2011). https://doi. org/10.1007/s10450-011-9320-z

Budaeva, A. D., Zoltoev, E. V. Porous structure and sorption properties of nitrogen-containing activated carbon. Fuel, 89, 2623-2627 (2010). https://doi. org/10.1016/j.fuel.2010.04.016

Campo, M. C., Ribeiro, A. M., Ferreira, A. F., Santos, J. C., Lutz, C., Loureiro, J. M. , Rodrigues, A. E. Carbon dioxide removal for methane upgrade by a VSA process using an improved 13X zeolite. Fuel Processing Technology, 143, 185-194 (2016). https://doi.org/10.1016/j.fuproc.2015.11.024

Carreon, M. A., Li, S., Falconer, J. L., Noble, R. D. Alumina-supported SAPO-34 membranes for $\mathrm{CO}_{2} /$ $\mathrm{CH}_{4}$ separation. Journal of the American Chemical Society, 130, 5412-5413 (2008). https://doi. org/10.1021/ja801294f

Cavenati, S., Grande, C.A., Rodrigues,A.E. Adsorption equilibrium of methane, carbon dioxide, and nitrogen on zeolite $13 \mathrm{X}$ at high pressures. Journal of Chemical \& Engineering Data, 49, 1095-1101 (2004). https://doi.org/10.1021/je0498917
Chang, A. C., Chuang, S. S., Gray, M., Soong, Y. In-situ infrared study of $\mathrm{CO}_{2}$ adsorption on SBA15 grafted with $\gamma$-(aminopropyl) triethoxysilane. Energy \& Fuels, 17, 468-473 (2003). https://doi. org/10.1021/ef020176h

Chong, Z. R., Yang, S. H. B., Babu, P., Linga, P., Li, X.-S. Review of natural gas hydrates as an energy resource: Prospects and challenges. Applied Energy, 162, 1633-1652 (2016). https://doi.org/10.1016/j. apenergy.2014.12.061

Do, D. D. Fundamentals of pure component adsorption equilibria, World Scientific, 2, 13-70 (1998).

Faramawy, S., Zaki, T., Sakr, A.-E., Saber, O., AboulGheit, A., Hassan, S. The activity of Mg-Al layered double hydroxides intercalated with nitrogencontaining anions towards the removal of carbon dioxide from natural gas. Journal of Natural Gas Science and Engineering, 54, 72-82 (2018). https:// doi.org/10.1016/j.jngse.2018.04.002

Fatemi, S., Vesali-Naseh, M., Cyrus, M., Hashemi, J. Improving $\mathrm{CO}_{2} / \mathrm{CH}_{4}$ adsorptive selectivity of carbon nanotubes by functionalization with nitrogen-containing groups. Chemical Engineering Research and Design, 89, 1669-1675 (2011). https://doi.org/10.1016/j.cherd.2010.10.002

Foo, K. Y., Hameed, B. H. Insights into the modeling of adsorption isotherm systems. Chemical Engineering Journal, 156, 2-10 (2010). https://doi. org/10.1016/j.cej.2009.09.013

Garnier, C., Finqueneisel, G., Zimny, T., Pokryszka, Z., Lafortune, S., Défossez, P. D. C., Gaucher, E. C. Selection of coals of different maturities for $\mathrm{CO}_{2}$ Storage by modelling of $\mathrm{CH}_{4}$ and $\mathrm{CO}_{2}$ adsorption isotherms. International Journal of Coal Geology, 87, 80-86 (2011). https://doi.org/10.1016/j. coal.2011.05.001

Ghaznavi, F., Fatemi, S., Joda, M., $\mathrm{CO}_{2}-\mathrm{CH}_{4}$ phase equilibria on modified multi-walled carbon nanotubes using Gibbs excess energy models based on vacancy solution theory. The Canadian Journal of Chemical Engineering, 90, 769-776 (2012). https://doi.org/10.1002/cjce.20526

Gui, M. M., Yap, Y. X., Chai, S.-P., Mohamed, A. R. Multi-walled carbon nanotubes modified with (3-aminopropyl)triethoxysilane for effective carbon dioxide adsorption. International Journal of Greenhouse Gas Control, 14, 65-73 (2013). https:// doi.org/10.1016/j.ijggc.2013.01.004

Hu, H., Zhang, T., Yuan, S., Tang, S. Functionalization of multi-walled carbon nanotubes with phenylenediamine for enhanced $\mathrm{CO}_{2}$ adsorption. Adsorption, 23, 73-85 (2017). ${ }^{2}$ https://doi. org/10.1007/s10450-016-9820-y

Huang, H. Y., Yang, R. T., Chinn, D., Munson, C. L. Amine-grafted MCM-48 and silica xerogel as superior sorbents for acidic gas removal from 
natural gas. Industrial \& Engineering Chemistry Research, 42, 2427-2433 (2003). https://doi. org/10.1021/ie020440u

Ioannatos, G. E., Verykios, X. E. $\mathrm{H}_{2}$ storage on singleand multi-walled carbon nanotubes. International Journal of Hydrogen Energy, 35, 622-628 (2010). https://doi.org/10.1016/j.ijhydene.2009.11.029

Irani, M., Jacobson, A. T., Gasem, K. A., Fan, M. Modified carbon nanotubes/tetraethylenepentamine for $\mathrm{CO}_{2}$ capture. Fuel, 206, 10-18 (2017). https:// doi.org/10.1016/j.fuel.2017.05.087

Jin, K., Zhang, T., Ji, J., Zhang, M., Zhang, Y., Tang, S. Functionalization of MCM-22 by dual acidic ionic liquid and its paraffin absorption modulation properties. Industrial \& Engineering Chemistry Research, 54, 164-170 (2015). https://doi. org/10.1021/ie504327t

Jin, K., Zhang,T., Yuan, S., Tang, S. Regulation of isobutane/1-butene adsorption behaviors on the acidic ionic liquids-functionalized MCM-22 zeolite. Chinese Journal of Chemical Engineering, 26, 127-136 (2018). https://doi.org/10.1016/j. cjche.2017.05.023

Jing, S.-Y., Lee, H.-J., Choi, C. K. Chemical bond structure on Si-OC composite films with a low dielectric constant deposited by using inductively coupled plasma chemical vapor deposition. Journal of the Korean Physical Society, 41, 769-773 (2002).

Kajama, M. N., Yildirim, Y., Taura, U. H., Grema, A. S., Abdulrahman, S. Silica Modified Membrane for Carbon Dioxide Separation from Natural Gas. Nano Hybrids and Composites, 21, 43-52 (2018). https:// doi.org/10.4028/www.scientific.net/NHC.21.43

Keller, L., Ohs, B., Lenhart, J., Abduly, L., Blanke, P., Wessling, M. High capacity polyethylenimine impregnated microtubes made of carbon nanotubes for $\mathrm{CO}_{2}$ capture. Carbon, 126, 338-345 (2018). https://doi.org/10.1016/j.carbon.2017.10.023

Khalili, S., Ghoreyshi, A. A., Jahanshahi, M., Pirzadeh, K. Enhancement of Carbon Dioxide Capture by Amine-Functionalized Multi-Walled Carbon Nanotube. Clean-Soil, Air, Water, 41, 939-948 (2013). https://doi.org/10.1002/clen.201200339

Khoerunnisa, F., Minami, D., Fujimori, T., Hong, S., Choi, Y., Sakamoto, H., Endo, M., Kaneko, K. Enhanced $\mathrm{CO}_{2}$ adsorptivity of SWCNT by polycyclic aromatic hydrocarbon intercalation. Adsorption, 20, 301-309 (2014). https://doi. org/10.1007/s10450-013-9578-4

Lajunen, A., Lipman, T. Lifecycle cost assessment and carbon dioxide emissions of diesel, natural gas, hybrid electric, fuel cell hybrid and electric transit buses. Energy, 106, 329-342 (2016). https://doi. org/10.1016/j.energy.2016.03.075

Lei, G., Liu, C., Xie, H., Song, F. Separation of the hydrogen sulfide and methane mixture by the porous graphene membrane: Effect of the charges. Chemical Physics Letters, 599, 127-132 (2014). https://doi.org/10.1016/j.cplett.2014.03.040

Li, H., Zhang, T., Yuan, S., Tang, S. MCM-36 zeolites tailored with acidic ionic liquid to regulate adsorption properties of isobutane and 1-butene. Chinese Journal of Chemical Engineering, 24, 1703-1711 (2016). https://doi.org/10.1016/j. cjche.2016.05.033

Li, J.-R., Kuppler, R. J., Zhou, H.-C. Selective gas adsorption and separation in metal-organic frameworks. Chemical Society Reviews, 38, 14771504 (2009). https://doi.org/10.1039/b802426j

Lu, C., Bai, H., Wu, B., Su, F., Hwang, J. F. Comparative study of $\mathrm{CO}_{2}$ capture by carbon nanotubes, activated carbons, and zeolites. Energy \& Fuels, 22, 30503056 (2008). https://doi.org/10.1021/ef8000086

Luebke, D., Myers, C., Pennline, H. Hybrid membranes for selective carbon dioxide separation from fuel gas. Energy \& Fuels, 20, 1906-1913 (2006). https:// doi.org/10.1021/ef060060b

Palmer, J. C., Moore, J. D., Roussel, T. J., Brennan, J. K., Gubbins, K. E. Adsorptive behavior of $\mathrm{CO}_{2}$, $\mathrm{CH}_{4}$ and their mixtures in carbon nanospace: a molecular simulation study. Physical Chemistry Chemical Physics, 13, 3985-3996 (2011). https:// doi.org/10.1039/c0cp02281k

Pawar, R. R., Patel, H. A., Sethia, G., Bajaj, H. C. Selective adsorption of carbon dioxide over nitrogen on calcined synthetic hectorites with tailormade porosity. Applied Clay Science, 46, 109-113 (2009). https://doi.org/10.1016/j.clay.2009.07.009

Peng, X., Wang, W., Xue, R., Shen, Z. Adsorption separation of $\mathrm{CH}_{4} / \mathrm{CO}_{2}$ on mesocarbon microbeads: experiment and modeling. AIChE Journal, 52, 9941003 (2006). https://doi.org/10.1002/aic.10723

Przepiórski, J., Skrodzewicz, M., Morawski, A. W. High temperature ammonia treatment of activated carbon for enhancement of $\mathrm{CO}_{2}$ adsorption. Applied Surface Science, 225, 235-242 (2004). https://doi. org/10.1016/j.apsusc.2003.10.006

Purna Chandra Rao, G., Satyaveni, S., Ramesh, A., Seshaiah, K., Murthy, K. S. N., Choudary, N. V. Sorption of cadmium and zinc from aqueous solutions by zeolite 4A, zeolite $13 \mathrm{X}$ and bentonite. Journal of Environmental Management, 81, 265-272 (2006). https://doi.org/10.1016/j. jenvman.2005.11.003

Shen, Y., Bai, J. A new kind $\mathrm{CO}_{2} / \mathrm{CH}_{4}$ separation material: open ended nitrogen doped carbon nanotubes formed by direct pyrolysis of metal organic frameworks. Chemical Communications, 46, 1308-1310 (2010). https://doi.org/10.1039/ b913820j

$\mathrm{Su}, \mathrm{F}$., Lu, C., Chen, H.-S. Adsorption, desorption, and thermodynamic studies of $\mathrm{CO}_{2}$ with high-amine- 
loaded multiwalled carbon nanotubes. Langmuir, 27, 8090-8098 (2011). https://doi.org/10.1021/ la201745y

Su, F., Lu, C., Cnen, W., Bai, H., Hwang, J. F. Capture of $\mathrm{CO}_{2}$ from flue gas via multiwalled carbon nanotubes. Science of The Total Environment, 407, 3017-3023 (2009). https://doi.org/10.1016/j. scitotenv.2009.01.007

Su, F., Lu, C., Kuo, S.-C., Zeng, W. Adsorption of $\mathrm{CO}_{2}$ on amine-functionalized Y-type zeolites. Energy \& Fuels, 24, 1441-1448 (2010). https://doi. org/10.1021/ef901077k

Wang, S., Lu, L., Lu, X., Cao, W., Zhu, Y. Adsorption of binary $\mathrm{CO}_{2} / \mathrm{CH}_{4}$ mixtures using carbon nanotubes: Effects of confinement and surface functionalization. Separation Science and Technology, 51, 1079-1092 (2016). https://doi.org $/ 10.1080 / 01496395.2016 .1150296$
Xiang, Z., Cao, D., Lan, J., Wang, W., Broom, D. P. Multiscale simulation and modelling of adsorptive processes for energy gas storage and carbon dioxide capture in porous coordination frameworks. Energy \& Environmental Science, 3, 1469-1487 (2010). https://doi.org/10.1039/c0ee00049c

Zhang, C., Liu, Q., Xu, Z. Synthesis and characterization of non-crystalline mesoporous silicon oxynitride MCM-41 with high nitrogen content. Journal of Non-Crystalline Solids, 351, 1377-1382 (2005). https://doi.org/10.1016/j. jnoncrysol.2005.03.035

Zhou, Z., Anderson, C. M., Butler, S. K., Thompson, S. K., Whitty, K. J., Shen, T.-C., Stowers, K. J. Stability and efficiency of $\mathrm{CO}_{2}$ capture using linear amine polymer modified carbon nanotubes. Journal of Materials Chemistry A, 5, 10486-10494 (2017). https://doi.org/10.1039/C7TA02576A 